\title{
UDC residuo cero. Calculadora online da pegada ecolóxica
}

\author{
Soto, Manuel ${ }^{1}$; Varela, Alberto²

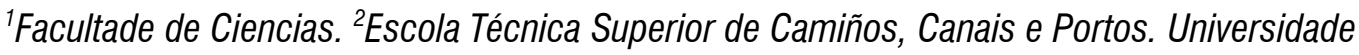 \\ da Coruña.
}

\section{RESUMO}

A universidade, como institución responsable da educación e a concienciación para a sustentabilidade, debe contribuír ao cambio cara a unha xestión sustentable dos residuos e cara a unha economía circular. Isto require divulgar os impactos dos residuos e das alternativas para reducilos, ademais de realizar unha xestión avanzada e exemplar dos residuos xerados na propia actividade. Como ferramenta para fomentar a concienciación e a implicación cidadá, nos últimos anos vénse facendo uso de diversas "calculadoras" do impacto ambiental (pegada ecolóxica, pegada do carbono, pegada hídrica, xeración de residuos, etc.). Porén, ningunha destas ferramentas ten sido desenvolvida en Galiza, en galego nin adaptada á realidade socio-económica e ambiental do noso país, ademais de ser escaso o uso e difusión daquelas existentes no ámbito próximo ou internacional. 0 presente traballo describe a concepción, o deseño e os primeiros resultados dunha enquisa online (en cursiva ao ser estranxeirismo; con todo, mellor sería en liña) sobre a xeración de residuos, a recollida separada na orixe e a súa pegada ecolóxica. A enquisa encóntrase dispoñible en https://emapic.es/custom/residuos-udc e pode ser utilizada por calquera persoa a título individual, por colectivos organizados ou por diferentes tipos de entidades, tanto con fins educativos no ensino formal como en actividades de sensibilización ambiental. (diferentes tamaños de letra)

PALABRAS CHAVE: Indicadores ambientais, Residuos, Consumo, Pegada ecolóxica. 


\section{CITA RECOMENDADA:}

Soto Castiñeira, M.; Varela García, F. A. (2018). UDC residuo cero. Calculadora online da pegada ecolóxica. En E. de la Torre Fernández (ed.) (2018). Contextos universitarios transformadores: retos e ideas innovadoras. II Xornadas de Innovación Docente. Cufie. Universidade da Coruña (páx. 207-224). DOI capítulo: https://doi.org/10.17979/spudc.9788497496780.207 DOl libro: https://doi.org/10.17979/spudc.9788497496780

\section{ABSTRACT}

The university, as an institution responsible for education and awareness for sustainability, should contribute to the change towards the sustainable waste management and the circular economy. This requires making known both the impacts of waste and the alternatives to reduce them, as well as carrying out an advanced management of generated waste at university activities. As a tool to promote awareness and citizen involvement, various "calculators" of the environmental impact (ecological footprint, carbon footprint, water footprint, waste generation, etc.) are in use in the few last years. However, none of these tools have been developed in Galicia, in Galician and adapted to the socioeconomic and environmental reality of our country. Besides, the use and dissemination of similar tools available in nearby countries or at the international level is scarce and hardly promoted. The present work describes the conception, design and first results of an online survey on the generation of waste, the separated collection at source, and the ecological footprint of waste. The survey is available at https://emapic.es/custom/residuos-udc. It can be used by anyone on an individual basis, by organized groups or by different types of entities, both for educational purposes in formal education and in environmental awareness activities.

KEY WORDS: Environmental indicators, Waste, Consumption, Ecological footprint. 


\section{INTRODUCIÓN}

A xeración de grandes cantidades de residuos é unha característica dos sistemas lineais de produción e consumo que definen as sociedades actuais como non sustentables. Neste marco, xorden como obxectivos a "economía circular" e a idea de "residuo cero", que xa teñen dado resultados na redución en orixe e na reutilización e reciclado dos residuos en numerosos ámbitos a nivel internacional. Son exemplos a filosofía "Residuo Cero", que engloba a municipalidades, colectivos sociais e entidades de diferentes tipo, ou a certificación "Residuo Cero" de AENOR, unha norma complementaria da ISO 14000.

0 movemento "Residuo Cero" (Zero Waste Europe, 2017) busca que as persoas adopten un comportamento compatible cos ciclos naturais, reducindo o volume e a toxicidade dos residuos e conservando e recuperando as materias primas, en vez de queimalas ou vertelas no medio. "Residuo Cero" significa cero vertido ao solo, á auga e ao aire de materias que poñan en perigo a saúde humana, dos animais e das plantas. No ámbito doméstico, son moitos os concellos e as cidades, en Europa e noutras partes, que teñen adoptado obxectivos "Residuo Cero", que se traducen na redución do $80-90$ \% dos residuos xerados. Na Galiza, pola contra, son case descoñecidas as prácticas e os programas de prevención da xeración de residuos, mentres que a recollida separada para a reciclaxe rolda non máis do 12 \% do total (Soto, 2016).

A universidade, como institución responsable da formación, da educación e da concienciación para a sustentabilidade, debe contribuír a cambiar esta situación, dando a coñecer tanto os impactos dos residuos como as alternativas para os reducir, ademais de realizar unha xestión avanzada e exemplar dos residuos xerados na propia actividade (Plana, 2013). Como ferramenta para fomentar a concienciación e a implicación cidadá, hai tempo que se vén facendo uso de diversas "calculadoras" do impacto ambiental (pegada ecolóxica, pegada do carbono, pegada hídrica, xeración de residuos, etc.). Ningunha destas ferramentas ten sido desenvolvida en Galiza, en galego nin adaptada á realidade socioeconómica e ambiental do noso país. Tampouco se ten promovido o seu uso e difusión, agás casos illados. 
0 obxectivo deste traballo é 0 de desenvolver e calibrar unha enquisa online relativa aos hábitos de compra e de consumo, que determinan a xeración de residuos, e á participación na separación selectiva dos residuos no fogar. Esta enquisa lévase a cabo no servizo web Emapic e pretende ser de utilidade tanto para diversas materiais de xestión de residuos impartidas na UDC como para o traballo a da Oficina de Medio Ambiente da UDC. Créase tamén como unha ferramenta de acceso libre co obxectivo de que poida ser empregada por calquera persoa, colectivo, empresa ou entidade.

\section{DESCRICIÓN DA EXPERIENCIA}

\subsection{0 servizo Emapic}

A calculadora online da pegada ecolóxica dos residuos consiste nunha enquisa aloxada en Emapic. Emapic é un servizo web desenvolto na UDC para facilitar a localización xeográfica de participantes en investigacións sociais ou en mapas de opinión. Ofrece recursos para representar cartograficamente os coñecementos e sentimentos da cidadanía. As súas capacidades desenvólvense máis alá dun servizo de creación de enquisas ao uso, pois é unha ferramenta de representación sobre mapas de calquera tipo de dato, facendo fincapé nos procesos colaborativos de participación, facilitando, deste xeito, os procesos de análise das dinámicas sociais. Actualmente, os traballos levados a cabo con Emapic permiten abranguer desde estudos de mobilidade, medioambientais ou de xeomarketing, até estudos de mellora da participación cidadá.

Na presente enquisa sobre residuos, para cada unha das preguntas formuladas asígnanse unha serie de pesos e ponderacións, que conseguen dar a cada participante unha cuantificación da súa pegada ecolóxica na compoñente residuos. Emapic recolle a localización xeográfica de cada persoa que responde, o que permite unha análise xeográfica dos resultados, valorando diferenzas entre ámbitos urbanos ou rurais, ou incluso entre zonas dentro dun mesmo municipio. 0 calibrado da enquisa requiriu un primeiro proceso participativo xeolocalizado. 
Para isto, a enquisa pide unha posición xeográfica (domicilio, etc.) da persoa que a cobre, de forma aproximada, para o que abonda con indicar un punto próximo (rúa ou barrio). Por outra banda, unha vez rematada a enquisa e enviadas as respostas, a calculadora mostra os resultados individuais da persoa que acaba de cubrila, a través de tres indicadores que veremos máis abaixo.

\subsection{Concepción básica da calculadora online}

A enquisa aborda os dous aspectos básicos que determinan 0 impacto ambiental dos residuos, condicionado polo noso estilo de vida e polas decisións que tomamos en dous eidos básicos:

a) na compra e no consumo fóra da casa, que determina a cantidade e 0 tipo de residuos que xeramos;

b) no fogar, que determina sobre todo 0 aproveitamento que se pode facer dos residuos para reducirmos o seu impacto ambiental.

Tanto a compra como a separación do lixo no fogar non son polo xeral cousa dunha única persoa. A enquisa busca saber os hábitos de compra e de xestión do lixo, con independencia de se se encarga destas tarefas a persoa que cobre a enquisa ou outra persoa que convive no fogar. Desta forma, require da persoa que a enche unha reflexión sobre aspectos da vida diaria dos cales en ocasións non é consciente. Se a persoa que cobre a enquisa non ten toda a información, deberá preguntar antes a quen no ámbito familiar se encarga de tales tarefas. En todo caso, a pesar deste carácter marcadamente colectivo das tarefas no fogar, fica unha marxe para as pautas de comportamento individuais, polo que pode ser cuberta polos diferentes membros do fogar con resultados en parte diferenciados.

Son 30 sinxelas preguntas que se poden contestar nuns 10 minutos. Cada pregunta (Táboa 1) refírese a un posible comportamento e presenta catro respostas opcionais indicativas da frecuencia con que se practica: «Sempre», «Moitas veces», «Poucas veces», «Nunca» (e «Non 0 consumo» nalgúns casos). 
A enquisa ten dúas seccións e sete apartados. Cada un destes apartados comeza cunha breve explicación que xulgamos necesaria para aclarar a intencionalidade e o significado das preguntas que se formulan (Táboa 2). Ademais, comeza cunha presentación e un apartado final no cal se piden os datos do perfil da persoa que a enche. Nesta última pregúntase a relación coa Universidade da Coruña (Estudante, PAS, PDI, Ningunha) e permite introducir un código de grupo, de utilidade para o seguimento dos resultados dun determinado grupo que teña decidido realizar a enquisa con ese código.

\subsection{Métodos de contabilización e de cálculo}

Estímase que unha persoa, que non ten en conta ningún dos criterios de redución da xeración de residuos, xera aproximadamente e de media $2 \mathrm{~kg}$ de $\mathrm{RU}$ por día; deles, $1,5 \mathrm{~kg} / \mathrm{d}$ de tipo non fermentable ou fracción seca (FS: envases, embalaxes e outros) e $0,5 \mathrm{~kg} / \mathrm{d}$ de residuos orgánicos fermentables, fracción húmida ou orgánica (F0). Non se ten en conta o poder adquisitivo ou a renda, que é un dos factores que inflúen na cantidade de residuos xerados, polo que este máximo é xa en si un valor medio.

$\mathrm{Na}$ enquisa facemos uso destes dous valores, 1,5 e $0,5 \mathrm{~kg} / \mathrm{d}$, por separado como valores máximos para ir descontándolle a redución que resulte de cada pregunta da enquisa. Isto dános unha xeración total máxima de $2 \mathrm{~kg} / \mathrm{d}$. A media en Galiza é máis baixa, aproximadamente de $1,2 \mathrm{~kg} / \mathrm{d}$ por persoa, mais temos que considerar que a maioría das persoas sempre aplican algunha medida de prevención, incluso sen sabelo, en relación co máximo. 
Táboa 1. Relación de preguntas (1 a 30) que conforman a versión inicial da enquisa.

\begin{tabular}{|c|c|}
\hline 1 & $\begin{array}{l}\text { Levo o carro da compra e as bolsas reutilizables que preciso e pido na tenda que non me } \\
\text { dean bolsas. }\end{array}$ \\
\hline 2 & Levo caixas (tuppers) para o peixe, a carne, comida elaborada ou produtos similares. \\
\hline 3 & Levo o carro ou unha bolsa de man, mais non o resto de bolsas e tuppers. \\
\hline 4 & $\begin{array}{l}\text { Evito produtos de usar e tirar, tales como envases monodose de iogur ou doutras } \\
\text { sobremesas, salsas monodose, coitelas de afeitar dun só uso... }\end{array}$ \\
\hline 5 & Merco en tendas a granel, mais acepto que me envasen os produtos para levar. \\
\hline 6 & Merco en tendas a granel e levo os meus envases e bolsas reutilizables da casa. \\
\hline 7 & Consúmoa da billa ou da fonte, polo que non xero residuos no fogar. \\
\hline 8 & Merco a auga en garrafas de plástico de máis de 5 litros ou en botellas de vidro de litro. \\
\hline 9 & Compro a auga en botellas de plástico medianas (1,5 litros) e pequenas. \\
\hline 10 & Compro o leite en botella de vidro reutilizable. \\
\hline 11 & Compro o viño en tetrabrick (cartón) \\
\hline 12 & Compro a cervexa, os zumes e os refrescos en envases de vidro reutilizables. \\
\hline 13 & Compro a cervexa, os zumes e os refrescos en botellas grandes (1 litro ou máis) \\
\hline 14 & Compro a cervexa, os zumes e os refrescos en botellas pequenas ou en botes. \\
\hline 15 & $\begin{array}{l}\text { Rexeito a vaixela dun só uso, como os vasos de cartón para o café ou os pratos para as } \\
\text { festas e pícnics. }\end{array}$ \\
\hline 16 & $\begin{array}{l}\text { Escollo non consumir sobremesas e bebidas en envases individuais (auga, refrescos, } \\
\text { iogures...). }\end{array}$ \\
\hline 17 & No restaurante, pido que me dean para a casa a comida sobrante. \\
\hline 18 & Procuro non utilizar vaixela de usar e tirar nas festas e comidas en grupo na casa. \\
\hline 19 & Utilizo panos de mesa de tea e non de papel. \\
\hline 20 & Recollo 0 aceite vexetal usado (de cociñar) para reciclar. \\
\hline 21 & Utilizo o papel de escritura polas dúas caras. \\
\hline 22 & 0 papel de escritura que compro é papel reciclado. \\
\hline 23 & Cada semana tiro ao lixo alimentos ou comida cociñada. \\
\hline 24 & Separo todo o vidro de envases e lévoo ao colector de vidro. \\
\hline 25 & Separo todo o papel e cartón e lévoo ao colector azul. \\
\hline 26 & $\begin{array}{l}\text { Separo os residuos de envases (botes metálicos, plásticos e bricks) e lévoos ao colector } \\
\text { amarelo. }\end{array}$ \\
\hline 27 & $\begin{array}{l}\text { Separo a materia orgánica dos demais residuos e fago compostaxe doméstica (ou } \\
\text { comunitaria) de todos os restos orgánicos. }\end{array}$ \\
\hline 28 & $\begin{array}{l}\text { Separo a materia orgánica (restos de comida e de facer a comida) dos demais residuos e } \\
\text { lévoos ao seu colector específico. }\end{array}$ \\
\hline 29 & Separo os residuos perigosos (pilas e baterías, medicamentos, produtos químicos...). \\
\hline 30 & $\begin{array}{l}\text { Levo os voluminosos (electrodomésticos, colchóns...) ao punto limpo, ou chamo ao servizo } \\
\text { organizado polo concello. }\end{array}$ \\
\hline
\end{tabular}


Táboa 2. Seccións e apartados da enquisa, e textos explicativos ao comezo de cada apartado.

\begin{tabular}{|c|c|}
\hline Sección/apartado & Texto explicativo \\
\hline $\begin{array}{l}\text { Sección } 1 . \\
\text { Na compra e no consumo } \\
\text { fóra da casa: oportunidades } \\
\text { para reducirmos os } \\
\text { residuos }\end{array}$ & $\begin{array}{l}0 \text { modelo de comercio imperante, e mesmo os intereses das grandes } \\
\text { cadeas de comercialización, impuxeron unhas prácticas de compra que } \\
\text { implican a xeración de grandes cantidades de residuos de envases e } \\
\text { envoltorios; residuos cuxa recollida e tratamento temos que pagar toda } \\
\text { a cidadanía, e que incluso cando son tratados continúan a xerar un } \\
\text { forte impacto ambiental na forma de emisións contaminantes dos } \\
\text { vertedoiros e plantas incineradoras. }\end{array}$ \\
\hline $\begin{array}{l}\text { Na compra, levo carro e } \\
\text { bolsas da casa, ou incluso } \\
\text { tuppers para o peixe e a } \\
\text { carne? }\end{array}$ & $\begin{array}{l}\text { Se somos conscientes deste impacto e queremos reducilo, temos } \\
\text { moitas oportunidades na hora da compra. Se non probaches a levar a } \\
\text { caixa do peixe e da carne da casa (os tuppers), non dubides en facelo: } \\
\text { verás que é moito máis práctico e hixiénico, ademais de evitar xerar } \\
\text { moitos residuos! }\end{array}$ \\
\hline $\begin{array}{l}\text { Compra de produtos de } \\
\text { usar e tirar e compra en } \\
\text { tendas a granel }\end{array}$ & $\begin{array}{l}0 \text { sobreenvasado e os produtos de usar e tirar xeran grandes } \\
\text { cantidades de residuos en relación á cantidade de produto e ao servizo } \\
\text { que prestan. Pola contra, a compra a granel (hortalizas, froitas, froitos } \\
\text { secos, cereais...) permite reducir os residuos, sobre todo se levamos } \\
\text { envases e bolsas da casa. }\end{array}$ \\
\hline $\begin{array}{l}\text { A auga que consumo } \\
\text { habitualmente }\end{array}$ & $\begin{array}{l}\text { En Galiza, a calidade da auga da billa é similar á das mellores augas } \\
\text { envasadas, aínda que o seu sabor non nos guste a todos/as. Mais non } \\
\text { esquezamos que o gusto se educa, e un par de horas de repouso } \\
\text { despois de collela elimínalle todo o sabor a cloro. Consumindo auga da } \\
\text { billa, aforras cartos e residuos! }\end{array}$ \\
\hline Leite e outras bebidas & $\begin{array}{l}\text { Temos unha gama de opcións moi ampla na compra deste tipo de } \\
\text { produtos, polo que só preguntaremos por algunhas. Evitarmos os } \\
\text { envases pequenos e optarmos polo vidro reutilizable (ollo!: o envase } \\
\text { reutilizable é aquel que se devolve á tenda, non o que se leva ao } \\
\text { contedor de reciclaxe) son as opcións que reducen residuos. }\end{array}$ \\
\hline Nas comidas fóra da casa & $\begin{array}{l}\text { Do prato ao tupper! No restaurante pagas polo que pides: se non } \\
\text { acabas a comida, podes levala para a casa. }\end{array}$ \\
\hline \multicolumn{2}{|l|}{$\begin{array}{l}\text { Sección } 2 . \\
\text { No fogar: máis prevención e } \\
\text { separación dos residuos }\end{array}$} \\
\hline $\begin{array}{l}\text { Practico as seguintes } \\
\text { medidas de redución en } \\
\text { orixe }\end{array}$ & $\begin{array}{l}\text { No noso día a día temos moitas oportunidades para reducir a xeración } \\
\text { de residuos e o seu impacto ambiental. Evitar que se nos perdan os } \\
\text { alimentos ou facer compostaxe dos restos non comestibles son } \\
\text { algunhas das máis importantes, mais non as únicas! }\end{array}$ \\
\hline $\begin{array}{l}\text { Realizo a separación dos } \\
\text { residuos nas seguintes } \\
\text { fraccións e lévoas ao } \\
\text { colector que lle corresponde }\end{array}$ & $\begin{array}{l}\text { A separación dos residuos por tipos segundo o plan municipal de } \\
\text { xestión é a medida que está nas nosas mans para acadar unha xestión } \\
\text { máis ecolóxica nos residuos que non conseguimos evitar. } 0 \text { vidro, o } \\
\text { papel, os envases e a materia orgánica son } 080 \% \text { do lixo, e poden ser } \\
\text { reciclados nas industrias creando postos de traballo! }\end{array}$ \\
\hline
\end{tabular}


Táboa 3. Escalas de expresión do resultado e mensaxe que se dá en función deste.

\begin{tabular}{|c|c|}
\hline Resultado & Mensaxe \\
\hline $\begin{array}{l}\text { A) }<0.5 \\
\mathrm{~kg} / \mathrm{d}\end{array}$ & Parabéns! Xeración de residuos moi baixa, inferior ao 50 \% da media galega. \\
\hline $\begin{array}{l}\text { B) } 0.5-1,0 \\
\mathrm{~kg} / \mathrm{d}\end{array}$ & $\begin{array}{l}\text { Xeración de residuos baixa, do xx\% }{ }^{\text {b }}(50-80 \%) \text { da media galega. Animámoste a } \\
\text { manter e seguir mellorando as túas prácticas de compra baixa en residuos. }\end{array}$ \\
\hline $\begin{array}{l}\text { C) } 0.5-1,0 \\
\mathrm{~kg} / \mathrm{d}^{\mathrm{a}}\end{array}$ & $\begin{array}{l}\text { Xeración de residuos baixa, do xx\% b }(50-80 \%) \text { da media galega, grazas á práctica da } \\
\text { compostaxe doméstica, mais poderías reducila moito máis se tiveses en conta } \\
\text { algunhas das opcións de redución de envases e embalaxes. }\end{array}$ \\
\hline $\begin{array}{l}\text { D) } 1-1,5 \\
\mathrm{~kg} / \mathrm{d}\end{array}$ & $\begin{array}{l}\text { Xeración de residuos alta, un } \mathrm{xx} \%^{\mathrm{b}}(85-125 \%) \text { da media galega. Aplicas algunhas } \\
\text { medidas de redución en orixe, mais está nas túas mans poder facer moito máis, pois } \\
\text { baixar de } 1 \mathrm{~kg} / \mathrm{d} \text { non é difícil de acadar. }\end{array}$ \\
\hline $\begin{array}{l}\text { E) }>1,5 \\
\mathrm{~kg} / \mathrm{d}\end{array}$ & $\begin{array}{l}\text { Xeración de residuos moi alta, un xx\% }{ }^{\text {b }}(125-170 \%) \text { da media galega. } 0 \text { teu estilo de } \\
\text { vida implica unha elevada xeración de residuos, xa que non tes en conta ningunha das } \\
\text { opcións de prevención que che permitirían reducir á menos da metade os residuos } \\
\text { xerados. }\end{array}$ \\
\hline
\end{tabular}

${ }^{a}$ Caso de realizar a práctica de compostaxe doméstica, pregunta 27 . ${ }^{\mathrm{b}}$ Non se dá o rango senón a \% numérica sobre a media galega.

\subsection{1. Índice de xeración de residuos e redución en orixe}

En función do potencial de redución, asígnase unha porcentaxe de redución, ben de residuos orgánicos que se poden destinar a compostaxe (opcións 17, 23 e 27), ben de fracción seca (0 resto de opcións). Algunhas opcións son neutras en canto a cantidade xerada (a 9 e a 22) e tamén as relativas a recollida separada (24-26 e 28-30), e só unha penaliza (a 11).

Cos pesos asignados e sobre a xeración de residuos máxima, o potencial máximo para redución é do 89 \% de FS e do $90 \%$ de F0, e a xeración mínima queda en 0,22 kg/d (0,17 de FS e 0,05 de F0). Consideramos conveniente empregar estas dúas bases de cálculo (xeracións máximas de 1,5 kg FS/d e 0,5 kg F0/d), xa que constitúen dous tipos de residuos moi diferentes en todos os aspectos que imos considerar.

Para os diferentes niveis de participación, en función da frecuencia elixida, asignáronse as seguintes porcentaxes de redución: 


\begin{tabular}{|l|l|l|l|l|}
\hline Frecuencia & Sempre & Moitas veces & Poucas veces & Nunca \\
\hline Preguntas 14 e 23 & $0 \%$ & $25 \%$ & $50 \%$ & $100 \%$ \\
\hline Resto de preguntas & $100 \%$ & $50 \%$ & $25 \%$ & $0 \%$ \\
\hline
\end{tabular}

Nalgunhas das preguntas, aínda que o formulario permite escoller "sempre" en dúas ou máis preguntas en que esa resposta "sempre" non sería realista, o método de cálculo si o ten en conta para evitar contabilizar medidas de redución redundantes. Os casos que aplican este criterio son os dos pares de preguntas 5-6, 7-8, e 12-13.

0 resultado de xeración poderá ir de 0,20 a 2,0 kg/d e persoa. 0 resultado obtido compárase coa xeración media en Galiza, de 1,2 kg/día por persoa, e indícase se a porcentaxe é mais alta ou máis baixa que a media. Escolléronse as escalas indicadas na Táboa 3, en función das cales se transmite unha mensaxe á persoa que realizou a enquisa.

Na Táboa 3, as opcións B e C teñen o mesmo rango de xeración; non obstante, mentres a B corresponde a alguén que non fai compostaxe doméstica mais cun consumo/compra moi baixo en residuos, a C corresponde a alguén que composta mais non ten en conta moitos dos criterios de redución na compra. Interesa diferenciar estes dous casos, xa que a mensaxe debe ser distinta.

\subsubsection{Resultado en canto á recollida selectiva (RS)}

Para estimar a recollida selectiva, en porcentaxe sobre a cantidade de residuos xerados pola mesma persoa, procedemos a dar un peso a cada tipo de material declarado (preguntas 24 a 30: Vidro, 7\%; P/C, 15\%; Residuos de envases (EnL), 14\%; F0 para colector especifico (Nostián-Barbanza) ou para compostaxe caseira, 45\%; Perigosos, 5\%; Voluminosos, 3\%). Nos ámbitos Nostián-Barbanza asinamos un 54 \% a F0, 0 que xa leva incluído 0 efecto sofre (sobre?) a fracción FS adicional ás outras fraccións V e P/C. En compostaxe doméstica, asinamos un $40 \%$ a esta, e contabilizamos os EnL (suma $54 \%$ ). 


\subsubsection{Pegada ecolóxica (pegada do carbono)}

As emisións de $\mathrm{CO}_{2}$ obtéñense multiplicando os residuos xerados sen recollida separada por un factor de emisión. 0 valor de referencia deste factor habitualmente empregado é de 0,61 kg $\mathrm{CO}_{2} / \mathrm{kg}$ residuo (Soto e Pérez, 2010), se ben se trata dun valor baixo en relación coa situación de SOGAMA que determina a situación galega (Soto, 2016). Aos residuos recollidos selectivamente e reciclados de forma eficiente non se lle asignan emisións.

Ao final da enquisa, dáse o resultado en $\mathrm{kg} \mathrm{CO}_{2}$ /ano, obtido pola ecuación:

PER (Pegada ecolóxica dos residuos non reciclados, $\left.\mathrm{kg} \mathrm{CO}_{2} / \mathrm{ano}\right)=$ Residuo $(\mathrm{kg} / \mathrm{d})^{*}(1-$ $\% \mathrm{RS} / 100)^{*} 0,61\left(\mathrm{kgCO}_{2} / \mathrm{kg}\right.$ Residuo $) * 365$ días/ano.

Para a media galega ( $1,2 \mathrm{~kg}$ residuos/día, $12 \%$ de RS), a PER resulta de $235 \mathrm{~kg} \mathrm{CO} /$ ano. 0 máximo (2,0 kg/d, $0 \%$ de recollida selectiva) sitúase en $445 \mathrm{~kg} \mathrm{CO} / \mathrm{ano}$.

\subsection{Expresión dos resultados}

A cada persoa que cobre a enquisa ofrécenselle os seus resultados persoais, definidos a través de 3 indicadores numéricos:

- Residuos xerados: xx kg/día

- Porcentaxe de recollida selectiva: xx \%

- Pegada ecolóxica (pegada do carbono): $x x ~ k g ~ \mathrm{CO}_{2} / \mathrm{ano}$

Ademais, en función do primeiro dos indicadores, emítese unha mensaxe relativa ao comportamento ambiental que manifesta, de acordo co indicado na Táboa 3.

\subsection{Calibrado}

A presente versión da enquisa constitúe a versión inicial, suxeita a modificacións en función dos resultados de calibración que se comezaron a facer e continuarán a facer ao longo do presente curso 2017/2018. A análise das primeiras mostras, cun total de 100 enquisas realizadas por tres colectivos diferentes (PDI da UDC, Estudantes da UDC, Persoas alleas á UDC) permitiu unha primeira avaliación do método de cálculo, así como da compresión xeral 
da enquisa, e das principais dificultades ou deficiencias que se queren resolver. Estes resultados detállanse no seguinte apartado.

\section{RESULTADOS}

\subsection{Resultados cuantitativos}

Emapic ofrece a calquera persoa que se achegue á enquisa os resultados de xeración de residuos distribuídos por rangos de xeración, segundo se indica na Figura 1. No caso das primeiras 100 enquisas, os resultados indican que $055 \%$ das respostas se sitúan no rango de 1 a 1,5 kg/d, arredor da media galega. 0 resto das respostas colócanse por debaixo (26\%) ou por riba (19\%) deste rango medio. A Táboa 4 dános os resultados para os tres indicadores. Estes resultados indican que a xeración de residuos resulta estimada de forma axeitada polo método empregado na enquisa. Porén, a porcentaxe de recollida selectiva resulta claramente moi superior á media, e tamén maior do que cabe xulgar por diferentes datos alleos ao contido da enquisa.

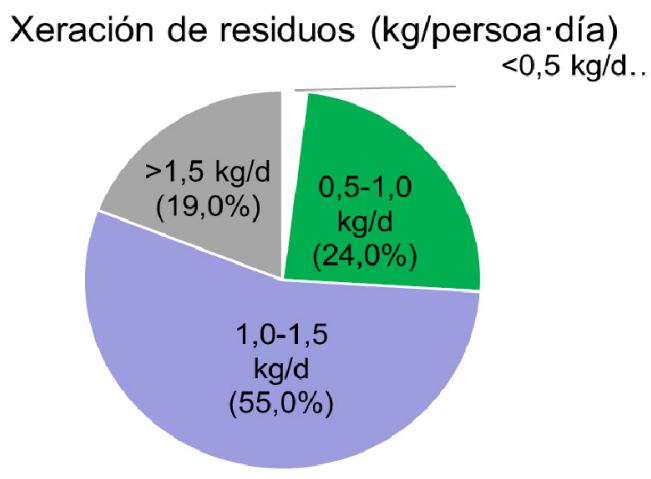

Figura 1. Resultados xerais mostrados pola aplicación Emapic. 
Táboa 4. Resultados globais obtidos para os tres indicadores ( $N=100)$

\begin{tabular}{lccc}
\hline & $\begin{array}{c}\text { Residuos xerados } \\
(\mathrm{kg} / \mathrm{d} \text { á) }\end{array}$ & Residuos separados (\%) & $\begin{array}{c}\text { Pegada ecolóxica (kg } \\
\left.\mathrm{CO}_{2} / \mathrm{ano}\right)\end{array}$ \\
\hline Media & 1,23 & 64,8 & 103,6 \\
Desv. Est. & 0,31 & 24,9 & 90,8 \\
Máximo & 1,76 & 84,0 & 370,4 \\
Mínimo & 0,41 & 0,0 & 14,6 \\
\hline
\end{tabular}

Os resultados foron avaliados tamén para 0 ámbito Nostián de xestión de residuos (A Coruña) e para 0 ámbito SOGAMA (outros concellos con respostas) (Táboa 5). A xeración de residuos foi significativamente menor no ámbito Non UDC, o que se pode explicar polo perfil das persoas participantes neste colectivo, mentres que non presenta diferenzas entre Estudantes e PDI no ámbito UDC. No que se refire á separación de residuos, o PDI declarou unha separación significativamente maior que o estudantado. Porén, chama a atención 0 alto valor da separación de residuos no ámbito non UDC (SOGAMA), que non a permite agás que 0 cidadán practique a compostaxe doméstica. Esta práctica, máis frecuente neste colectivo da enquisa, explica en parte os resultados, pero precisa máis estudo con poboacións específicas representativas deste ámbito.

Táboa 5. Resultados segundo o colectivo e ámbito xeográfico.

\begin{tabular}{llcr}
\hline Ámbito/Colectivo $^{*}$ & Estudantes UDC & PDI UDC & Non UDC \\
\hline Residuos xerados (kg/día) & $1,28 \pm 0,29^{\text {a }}$ & $1,28 \pm 0,25^{\mathrm{a}}$ & $1,15 \pm 0,35^{\mathrm{b}}$ \\
Residuos separados (\%) & $61,3 \pm 26,3^{\mathrm{a}}$ & $71,7 \pm 18,2^{\mathrm{b}}$ & $64,2 \pm 26,7^{\mathrm{a}}$ \\
\hline ámbito UDC corresponde ao modelo Nostián, e o Non UDC ao modelo SOGAMA. Para cada fila, \\
rentes letras indican diferenzas significativas a un nivel de probabilidade do $90 \%$.
\end{tabular}

A Figura 2 mostra a correlación entre a cantidade de residuos xerados e a práctica da separación das diversas fraccións no fogar. Unha parte significativa da mostra atinxe ao valor máximo de separación posible con independencia da cantidade de residuos xerados. Por outra banda, existe unha correlación altamente significativa e positiva entre a cantidade xerada e a 
non separación dos residuos. Identifícase un grupo caracterizado por unha elevada xeración de residuos (1,3-1,7 kg/d) e baixa separación en orixe (<30 \%).

\subsection{Resultados cualitativos}

A Táboa 6 presenta os resultados relativos á frecuencia de elección de cada unha das prácticas definidas nas diferentes preguntas da enquisa. Estes resultados non indican anomalías apreciables, e mostran a pertinencia de todas as opcións elixidas polo modelo. Alén disto, recibíronse comentarios dun número reducido de persoas colaboradoras que están a ser analizados no contexto de mellora da enquisa. Unha das consideracións é a relativa ao feito de que os textos introdutorios poden condicionar a resposta da persoa que está a cubrir a enquisa. Isto debe ser valorado na consideración do carácter educativo desta ferramenta, para 0 que xulgamos necesarios estes comentarios, mentres que 0 valor de medición debe considerarse de forma matizada.

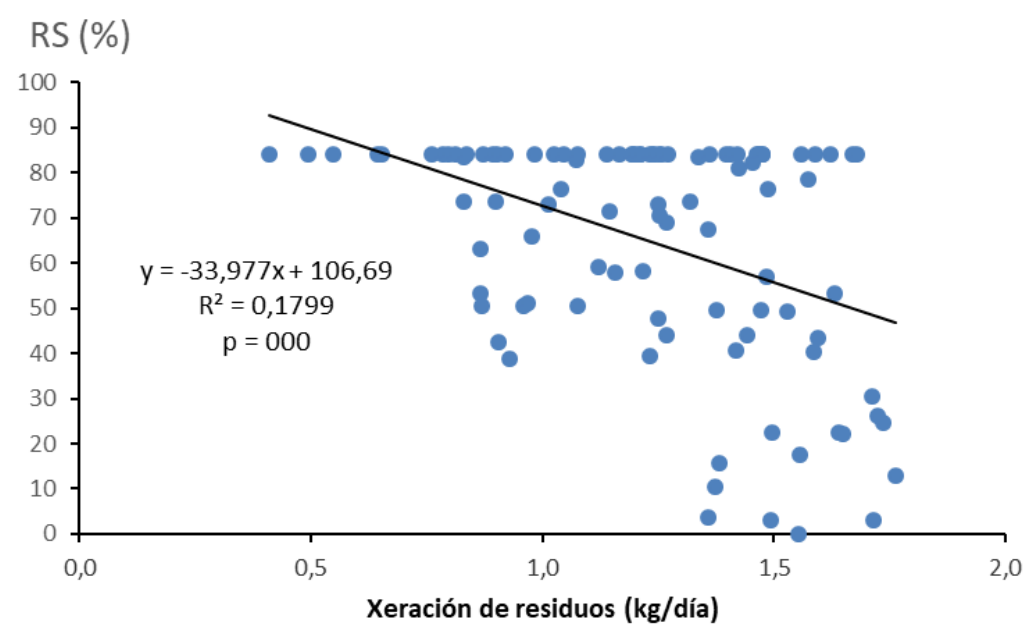

Figura 2. Correlación entre taxa de xeración e taxa de separación de residuos no fogar. 
Táboa 6. Clasificación das prácticas segundo a frecuencia declarada.

\begin{tabular}{lll}
\hline Frecuencia & Criterio & Prácticas (Preguntas) \\
\hline Opcións máis practicadas & Sempre $>50 \%$ e Sempre+Moitas & P7, P18, P20, P21, P25, P26, \\
& $\begin{array}{l}\text { veces }>70 \% \\
\text { Opcións frecuentemente }\end{array}$ & P29, P30 \\
practicadas & & P1, P3, P4, P14, P15, P19, \\
Opcións escasamente & Nunca + Poucas veces $>50 \%$ & P5, P9, P13, P16, P17, P22, \\
practicadas & & P23, P24 \\
Opcións menos practicadas & Nunca $>50 \%$ & P2, P6, P8, P10, P11, P12 \\
\hline
\end{tabular}

\subsection{Representación xeográfica das respostas}

A aplicación Emapic permite obter numerosos mapas en función da escala xeográfica e doutros criterios que se poden especificar para visualizar os resultados (Figura 3 e 4).

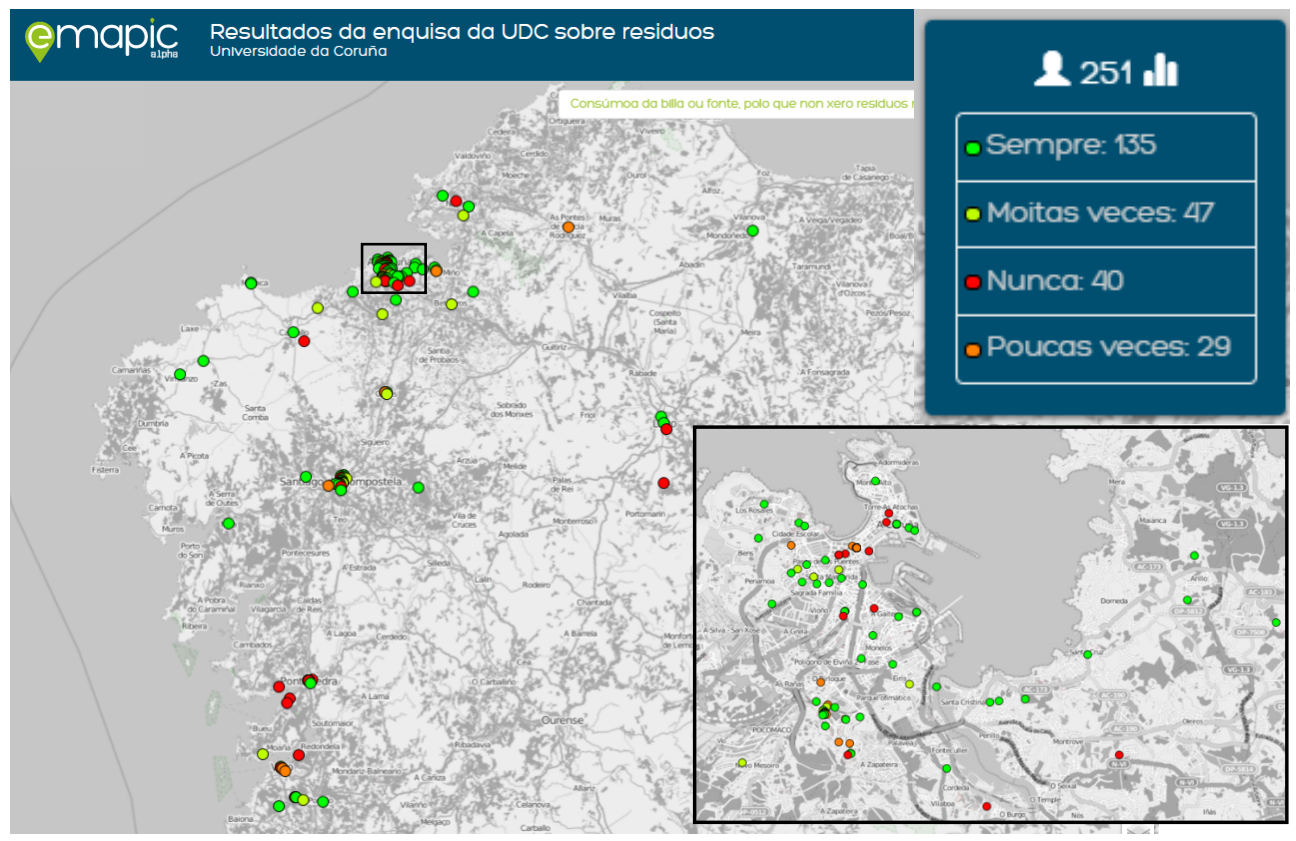

Figura 3. Distribución xeográfica das respostas á pregunta P7 “Consumo a auga da billa”. 


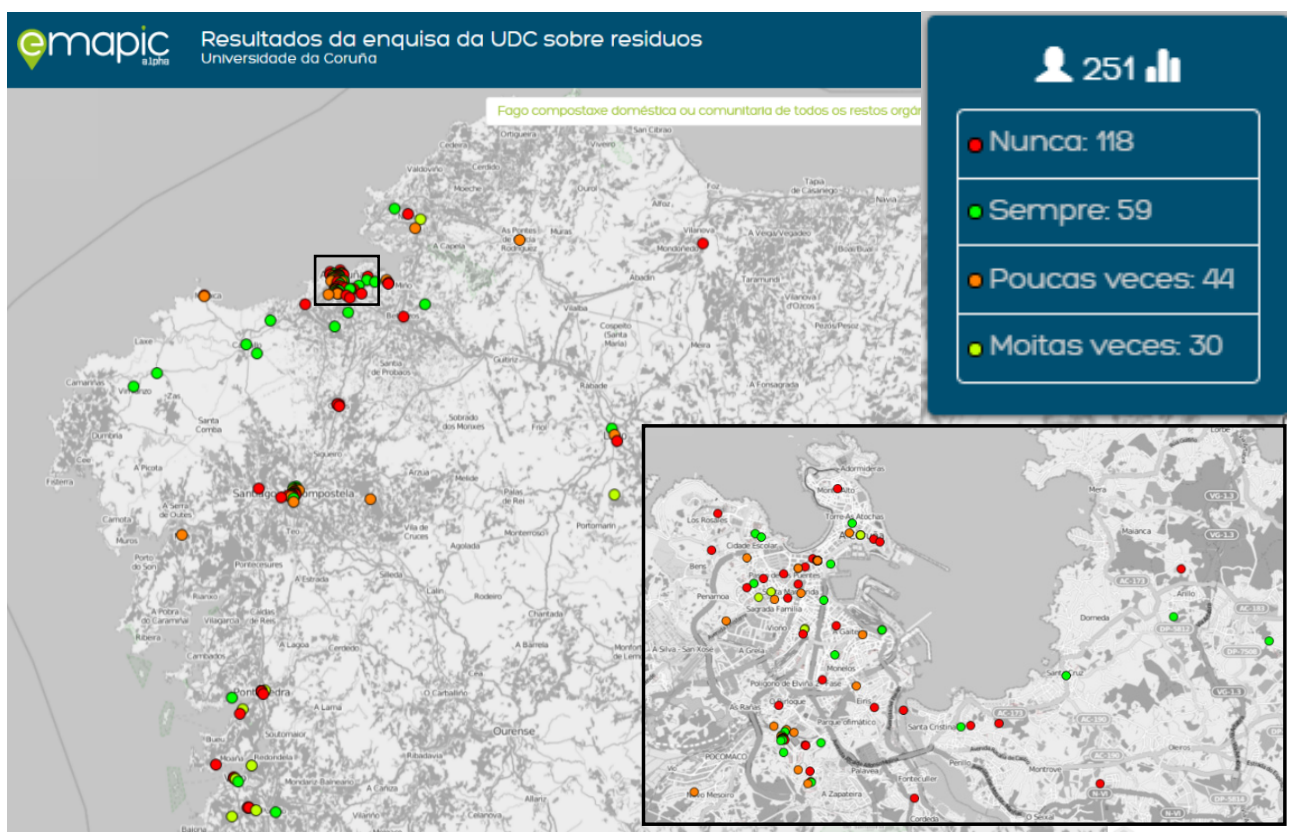

Figura 4. Distribución xeográfica das respostas á pregunta P27 "Fago compostaxe doméstica".

Os mapas das Figuras 3 e 4 foron obtidos na primeira semana de decembro de 2017, cando se rexistraba un total de 251 respostas, das cales 218 correspondía a Galiza. A Figura 3 mostra as respostas á pregunta "Consumo a auga da billa", unha opción que recibe unha maioría de respostas afirmativas, particularmente nas zonas rurais, mais tamén nas cidades. A redución da escala ampliado o mapa permite ver a localización das resposta, por exemplo, dentro dun mesmo ámbito urbano. A Figura 4 mostra as respostas á pregunta "Fago compostaxe doméstica", opción que non é maioritaria, pero que si recibe un número significativo de adhesións, e non é allea aos ámbitos urbanos.

\section{CONCLUSIÓNS}

Disponse desta ferramenta accesible en https://emapic.es/custom/residuos-udc e que pode ser utilizada por calquera persoa a título individual, por colectivos organizados ou por diferentes tipos de entidades, tanto con fins educativos no ensino formal como en actividades 
de sensibilización ambiental. Tras as fases primeiras de deseño e construción da enquisa, así como de análise dos primeiros resultados, obtemos as seguintes conclusións:

- Baséase nun modelo enfocado ao consumo, e por tanto á educación para a redución na orixe da xeración de residuos.

- É de realización simple, ao se basear nas actividades cotiás que practica cada persoa.

- Os resultados provisionais son realistas, ao menos cando se aplica á situación galega.

- É conveniente completar o estudo da súa aplicación por diferentes colectivos (centros de ensino non universitario, outras áreas xeográficas) para establecer o seu rendemento con maior claridade e fiabilidade.

- Os primeiros resultados suxiren a necesidade de reforzar a información referida aos modelos de xestión e opcións de recollida separada dispoñibles (ámbitos de xestión de Nostián, SOGAMA e Barbanza).

- Aproveitar o potencial dunha maior información gráfica sobre algunhas das prácticas de prevención da xeración de residuos e sobre a recollida separada e as súas consecuencias ambientais.

\section{REFERENCIAS}

- Plana, R. (2013). Plan de xestión de residuos Campus de Elviña e A Zapateira da Universidade da Coruña. Oficina de Medio Ambiente (OMA-UDC). (https://www.udc.es/arquivos/sites/udd/_galeria_down/sociedade/medio_ambiente/re siduos/ResiduosxELVxZAPATEIRAx2013.pdf; última consulta 07/12/2017).

- Soto, M. (2016). SOGAMA: A xestión do lixo que Galiza precisa? Cerna 76, pp. 10-13 (http://www.adega.gal/revistacerna/revistas.php?id=54\&idioma = gl\&sec =150; última consulta 07/12/2017).

- Soto, M., Pérez, M. (2010). A Pegada Ecolóxica da Universidade da Coruña. Oficina de Medio Ambiente (OMA-UDC). 
(https://www.udc.es/export/sites/udc/_galeria_down/sociedade/medio_ambiente/peg ada_ecoloxica/pegada.pdf; última consulta 07/12/2017).

- Zero Waste Europe (2017). What is zero waste? https://www.zerowasteeurope.eu/ (última consulta 07/12/2017). 